\title{
ANÁLISIS CRÍTICO DEL JUICIO POLÍTICO. ESPECIAL REFERENCIA AL ESTADO DE GUANAJUATO
}

\author{
Critical analysis of Impeachment. Special \\ reference to the state of Guanajuato
}

Vicente VÁZQUEZ BUSTOS

\section{Sumario:}

1. Introducción. 2. Consideraciones. 2.1. Algunos Antecedentes: El Impeachment Británico. 2.2. El Impeachmenten el sistema constitucional estadounidense. 3. Crítica del Juicio Político. 3.1. Referencia al Juicio Político en Guanajuato. 4. Bibliografía.

Resumen. La reciente reforma constitucional en materia del Sistema Nacional Anticorrupción, implicará un redimensionamiento y re conformación de los órganos encargados del combate a la corrupción, donde se involucra a la sociedad, además de crearse entes de relevancia constitucional; no obstante, la figura del Juicio Politico permaneció intocada, generando un desfase dada la obsolescencia de esta institución y su nula eficacia. En tal sentido, el presente artículo tiene por objeto hacer un análisis crítico de la figura del Juicio Político, a partir de los antecedentes del Impeachment Británico, así como en los Estados Unidos de América, para culminar con la crítica de la figura ante citada figura en el ordenamiento jurídico mexicano, con especial referencia al estado de Guanajuato.

Palabras Clave: Impeachment; Juicio Político; Sistema Nacional Anticorrupción.

Abstract. The recent constitutional reform on the National Anticorruption System, will involve downsizing and re establishment of the bodies responsible for combating corruption, which society is involved, along with relevant constitutional bodies created; However, the figure of Impeachment remained untouched, creating a lag given the obsolescence of this institution and no efficacy. In this sense, this article aims to make a critical analysis of the figure of Impeachment, from the history of British and American Impeachment, culminating in the critical figure to figure cited in the Mexican legal system, with particular reference to the state of Guanajuato.

Keywords: Impeachment; and National Anti-Corruption System.

\section{INTRODUCCIÓN}

La norma jurídica no es un instrumento estático, sino por el contrario, debe permanecer en un proceso constante de cambio, de perfeccionamiento, para resolver, por una parte, las

\footnotetext{
1 Licenciado en Derecho y Maestro en Fiscal. Director General de Agenda Legislativa y Reglamentación de la Coordinación General Jurídica de la Consejería y Enlace de Gubernatura.
} 
probables deficiencias y lagunas que contenga y, por otra parte, para que su contenido se mantenga acorde a la realidad que le corresponde regular; bajo este contexto y derivado de la coincidencia de las diversas fuerzas políticas representadas en ambas cámaras del Congreso de la Unión, el pasado 27 de mayo de 2015, se publicó en el Diario Oficial de la Federación la reforma constitucional en materia del Sistema Nacional Anticorrupción. ${ }^{2}$

El Sistema Nacional Anticorrupción es una instancia de coordinación entre las autoridades de todos los órdenes de gobierno competentes en la prevención, detección y sanción de responsabilidades administrativas y hechos de corrupción, así como en la fiscalización y control de recursos públicos.

El Sistema busca crear una instancia con capacidad de mejora continua del desempeño de la administración gubernamental; además de tener la capacidad técnica y objetiva para medir y evaluar al servidor público bajo los principios de legalidad, honradez, lealtad, imparcialidad y eficiencia en el desempeño de sus funciones, empleos, cargos y comisiones; los principios resultan imperantes y aplicables para los particulares que se ubiquen en cualquiera de estos supuestos, en especial cuando se afecte a la Hacienda Pública o el patrimonio de los entes públicos federales, locales o municipales. Su diseño legislativo converge en una instancia incluyente en todos los órdenes de gobierno al establecer como requisito indispensable para su funcionamiento la participación ciudadana.

El Sistema Nacional de Fiscalización se inscribe como un subsistema consolidado y autónomo, pero funcionando como eje central y pilar fundamental del Sistema Nacional Anticorrupción; así, las acciones emprendidas por el Estado para prevenir y sancionar la corrupción, no se llevarán a cabo de forma aislada o fragmentada, sino como un sistema integral articulado para prevenir y sancionar las responsabilidades administrativas y los hechos de corrupción, sea que éstas deriven del ejercicio indebido de los recursos públicos o bien, del incumplimiento de responsabilidades públicas que no se vinculan necesariamente con la hacienda pública.

Se contempla la creación de un Comité de Participación Ciudadana, con lo que se fortalecen sus funciones, se aglutinan esfuerzos y se encaminan de manera eficaz las propuestas ciudadanas. El Comité estará conformado por cinco ciudadanos que se hayan destacado por su contribución a la transparencia, la rendición de cuentas o el combate a la corrupción; así, el Sistema Nacional Anticorrupción, busca dar pauta a un sistema integral y transversal, ale-

\footnotetext{
${ }^{2}$ Decreto por el que se reformaron los artículos 22, párrafo segundo, fracción II; 28, párrafo vigésimo, fracción XII; 41, párrafo segundo, fracción V, Apartado A, en sus párrafos segundo, octavo y décimo; 73, fracciones XXIV y XXIX-H; 74, fracciones II y VI, en sus párrafos segundo, tercero, cuarto y quinto; 76, fracción II; 79, párrafos primero, segundo, actual tercero y sus fracciones I, en sus párrafos segundo, cuarto y quinto, II y IV, primer párrafo, y los actuales párrafos cuarto, quinto y sexto; 104, fracción III; se modifica la denominación del Título Cuarto para quedar "De las Responsabilidades de los Servidores Públicos, Particulares Vinculados con faltas administrativas graves o hechos de Corrupción, y Patrimonial del Estado"; 109; 113; 114, párrafo tercero; 116, párrafo segundo, fracciones II, en su párrafo sexto y V; 122, Apartado C, BASE PRIMERA, fracción $V$, incisos c), en su párrafo segundo, e), m) y n) y, BASE QUINTA; se adicionan los artículos 73, con una fracción XXIX-V; 74, con una fracción VIII, pasando la actual VIII a ser IX; 79, con un tercer y cuarto párrafos, recorriéndose los actuales en su orden; 108, con un último párrafo; 116, párrafo segundo, fracción II, con un octavo párrafo, recorriéndose el actual en su orden; 122, Apartado C, BASE PRIMERA, fracción $\mathrm{V}$, inciso c), con un tercer párrafo, recorriéndose el actual en su orden; y se deroga el segundo párrafo de la fracción IV, del actual párrafo tercero del artículo 79 de la Constitución Política de los Estados Unidos Mexicanos.
} 
jado de intereses personales, pues sus finalidades son muy claras: generar mejores estándares en el servicio público y combatir de manera definitiva los actos de corrupción.

En síntesis, el Sistema Nacional Anticorrupción constituye un cambio de paradigma en nuestro sistema jurídico que demandó modificaciones de fondo a las facultades de las autoridades encargadas de prevenir, investigar, sancionar y corregir los actos y hechos de corrupción (entendidos los primeros en el ámbito administrativo y los segundos en el penal), y en consecuencia al andamiaje constitucional y legal que los regula; no obstante lo anterior, el Constituyente Permanente dejó subsistente la figura del Juicio Político, la cual, a la luz de los avances en materia de combate a la corrupción, constituye una figura no solo desfasada, sino obsoleta e ineficaz, cuya crítica es el objeto del presente artículo.

En primer lugar, se hará un análisis crítico de la figura del juicio político a partir de algunos antecedentes y la finalidad para la cual fue creado, todo ello con la intención de despejar algunas asunciones problemáticas del mismo al equipararse con otras figuras de otros sistemas políticos, en segundo lugar, realiza la crítica detallada de dicha figura.

\section{CONSIDERACIONES}

El escrutinio público y la rendición de cuentas es un tema que ha acompañado siempre a la función pública. Lo anterior es particularmente importante respecto de los altos cargos, dada su especial posición o relevancia para la correcta marcha de la administración del Estado. Ello los hace sujetos de un escrutinio más intenso. Todo el sistema de responsabilidad de los servidores públicos se construye sobre la base de estas premisas. El juicio político lato sensu forma parte integrante de ese sistema por el cual los propios ciudadanos, los representantes populares u otros funcionarios públicos colaboran con la finalidad de preservar adecuado accionar del gobierno. De forma más específica, podríamos decir que es un mecanismo para retirar la confianza depositada en los servidores públicos. Para ello se finca un tipo «especial» de responsabilidad dirigida a altos funcionarios por conductas consideradas graves.

Entre los antecedentes del juicio político en nuestro sistema jurídico destaca el llamado Impeachment del derecho constitucional norteamericano que, a su vez, deriva del commonlaw británico. En este último contexto, el juicio político está asociado a la prerrogativa que tienen los parlamentarios de fincar responsabilidad sobre sus pares. No obstante, no debe pasar por alto ese origen en el derecho parlamentario y sistema jurídico inglés y, de ahí, su migración al derecho constitucional estadounidense. La referencia no es menor, como veremos enseguida.

\subsection{AlgunOS ANTECEDENTES: EL IMPEACHMENT BRITÁNICO}

El procedimiento de Impeachment (del inglés toimpeach: «acusar a un funcionario público», «cuestionar la honestidad de alguien», «llamamiento a rendir cuentas»), surgió como un medio para que el parlamento pudiera ejercer algún control indirecto sobre el Rey a través de sus lugartenientes. Fue creado como una forma de rendición de cuentas de los «oficiales» del monarca. ${ }^{3}$ Para apreciar su relevancia, es preciso tener presente que en el Derecho inglés se considera que el Rey no puede cometer violación alguna a la Constitución y, por tanto, no es sujeto de juicio ante el Parlamento. En su núcleo, el Impeachment británico es reflejo

\footnotetext{
3 Véase la voz: «Impeachment» en el Glossary of ParliamentaryUsefulTerms del Parlamento Británico. En línea: http://www.parliament.uk/site-information/glossary/impeachment/
} 
de una filosofía política prevaleciente durante la edad media y que no es otra sino aquella basada: «en el ideal que se dirige a todos los gobernantes y príncipes, así como a sus oficiales, para conducirse respetando las leyes... consistía esencialmente en un tribunal para hombres, destacados por causas relevantes y eventualmente se ha creído que el mismo podría aplicarse a causas tales como lexParlamenti - una norma que para hacer justicia incluso cuando las leyes ordinarias no lo hubieran hecho-».4

Además de la finalidad aludida, otra de las señas de identidad Impeachmentes su procedencia contra "delitos y faltas graves»(highcrimes and misdemeanors). Así se hizo constar por primera vez en el año 1386 cuando se realizó el procedimiento contra Michael de la Pole, Consejero Real y Conde de Sulffolk. ${ }^{5}$ Algunas de las acusaciones vertidas contra el consejero consistían en la violación del commonlaw inglés - delitos incluidos-; pero otras acusaciones no tenían tal base. Posteriores procedimientos de este tipo contemplaban a menudo conductas que no se circunscribían a acciones delictuosas. Así, por ejemplo, en 1450, año en que William de la Pole — descendiente del Michael y Duque de Suffolk - fue sometido a Impeachment, se contemplaron nuevamente conductas que caían en el ámbito penal como fuera de él; conductas tales como «asesorar al rey para conceder privilegios y libertades a ciertas personas que obstaculizaban la debida ejecución de las leyes», «la adjudicación de oficinas y despachos a personas ineptas o indignas de ellas» $\mathrm{o}$ «despilfarrar el tesoro público». ${ }^{6}$

El núcleo de significado otorgado a highcrimes and misdemeanors, o lo que ha de entenderse por «delitos y faltas graves» en la que descansa su procedibilidad, constituye una de las cuestiones más importantes a propósito de la figura. Para rastrear ese significado el método más usual consiste en acudir a sus precedentes. Pues bien, el núcleo de significado en Inglaterra tienen que ver con los denominados «delitos» o «crímenes políticos», mismos que no tienen que ser necesariamente procesados o investigados desde el ámbito penal7. De ahí que se haya dicho que denotan «una categoría fuera del alcance de la reparación penal ordinaria». Así mismo, debe tenerse presente que se trata de conductas de los funcionarios reales que socaban el imperio de la ley que inciden gravemente en el correcto funcionamiento del gobierno. Entre las conductas se incluían: «la malversación de fondos», «el abuso del poder oficial», «la negligencia en el servicio público», «la invasión o el desacato a las prerrogativas parlamentarias» así como las "prácticas de corrupción» o «la traición a la confianza pública».

De conformidad con la práctica parlamentaria, y de forma sumaria, puede decirse que el procedimiento de Impeachment consiste en la petición formulada por un miembro de la Cámara de los Comunes ante la Cámara de los Lores para destituir a algún oficial del Rey por algún delito o falta grave. ${ }^{8} \mathrm{El}$ denunciante debía presentar los alegatos y pruebas suficientes para iniciar un juicio político. Si la Cámara de los Comunes encontraba suficientes indicios para proceder en juicio político, se requería al Speaker elegido para que acudiera a la Cámara de los Lores para solicitar solemnemente la instauración del procedimiento de juicio político

\footnotetext{
4 Véase: BROWN FIRMAGE, Edwin, «The Law of Presidential Impeachment», Utah Law Review, pp. 603-625, aquí pp. 682-3.

5 Ibidem.p. 683.

${ }^{6}$ Cf. BROWN FIRMAGE, Edwin, «The Law of Presidential Impeachment», cit.,aquí p. 684.

7 GEHART, Michael J., «The Lessons of Impeachment History», George Washington Law Review, num. 67, 1999, pp. 603-625, aquí p. 610.

${ }^{8}$ Que sea la Cámara de los Lores la que en última instancia juzgara se debe, fundamentalmente, a la observancia del principio de paridad de rango, toda vez que únicamente los iguales pueden juzgarse entre sí - esto es, la Cámara de los Lores está integrado por nobles, teniendo la misma «dignidad» que los oficiales reales sujetos a juicio-.
} 
«en nombre de la Cámara de los Comunes y de todos los Comunes del Reino». Para ello, seleccionaban a algunos miembros de la Cámara de los Comunes (Managers) que fungían como fiscales, encargándose de formular la acusación y hacer la solicitud para someter a alguna persona a juicio político. Una vez entregada la solicitud solemne de juicio político por el Speaker ante la Cámara de los Lores, a éstos corresponde sustanciar el procedimiento así como todas las comunicaciones entre la Cámara de los Comunes y el acusado. La Cámara de los Lores fijaba una fecha de audiencia, misma que se asemeja en su desahogo al procedimiento penal. Es decir, se trata de una audiencia en la que tanto la parte acusadora como el acusado pueden presentar pruebas y formular alegatos. Al final de la audiencia, los Lores deciden en votación el veredicto final que decide el caso sobre la base de una mayoría simple.

El último Impeachment del que se tiene registro en el Reino Unido tuvo lugar en el año de 1806. Lo anterior explica por qué, en gran medida, el juicio político se considere en la actualidad una institución anacrónica. En efecto, normalmente se entiende que el juicio político es una de las prerrogativas inherentes a la función parlamentaria de la House of Representatives en tanto órgano colegiadog (como lo es también la garantía de que por la mera declaración de opiniones resulta improcedente). Así fue puesto de relieve por el Select Committeeon Parliamentary Privilege en el año de 1967. En ese mismo año se planteó la pertinencia de suprimirlo formalmente, legislando expresamente para ello. Sin embargo, dicha normativa no se produjo. Esta recomendación volvió a repetirse en el tercer informe que el citado comité elaboró en el año 1976-1977. Casi una década después, en el Joined Committeeon Parliamentary Privilege Report de 1989se afirmó categóricamente que «las circunstancias que han dieron lugar al Impeachment son tan distintas a las presentes que el procedimiento puede ser considerado obsoleto». ${ }^{10}$

Que la institución del Impeachment estime ya obsoleto por parte de los parlamentarios británicos es dato que sin duda merma el atractivo de la figura. Ello, podría explicarse básicamente en el hecho de que su surgimiento en el siglo XIII estuvo ineludiblemente ligado al control del Rey y, sobre todo, al posterior ascenso del Parlamento como «soberano»-por así decir-, dando lugar a la supremacía parlamentaria en el sistema constitucional inglés. Una vez consumado tal ascenso del Parlamento, estableciéndose las bases definitivas de su sistema de Gobierno, la figura del Impeachment carece de utilidad dada la naturaleza fiduciaria que se establece entre el Gobierno y la mayoría Parlamentaria. En su seno, la pérdida o el retiro de la confianza pública de algún parlamentario o del gobierno tiene otros causes institucionales: ya sea a través de la remoción del Primer Ministro, ya sea a través de la disolución del Parlamento. De la misma forma, parece claro que en dicho contexto difícilmente puede producirse el bloqueo mutuo entre el Gobierno y el Parlamento (dada su relación fiduciaria) y toda vez que ambos tienen incentivos institucionales para encausar sus eventuales desavenencias políticas.

\subsection{EL IMPEACHMENT EN EL SISTEMA CONSTITUCIONAL ESTADOUNIDENSE}

La pertinencia de adaptar el Impeachment al naciente Estado norteamericano fue objeto de debate desde la propia formación de la Unión. De hecho, el procedimiento fue considerado a menudo como un recurso para intentar ejercer algún control sobre la Corona desde las

\footnotetext{
${ }^{9}$ GAY, Oonagh y DAVIES Neris, «Impeachment», House of Commons Library Standard Note, SN/PC/o2666, 2011, p. 3. Visible en: http://www.parliament.uk/briefing-papers/SNo2666/impeachment

${ }^{10}$ Ibid.p. 4.
}

CIENCIA JuRídicA. Departamento de Derecho. División de Derecho, Política y Gobierno, Universidad de Guanajuato - Año 5, No. 9, 2016 
colonias en el territorio americano, lo que redundó en su prestigio. ${ }^{11} \mathrm{Si}$ bien es innegable la vinculación de la institución a la tradición inglesa, no obstante, los constituyentes americanos (FoundingFathers) trataron de adaptar la figura al experimento de su nueva forma de organización política, dándole una configuración especial. Se han documentado algunos debates a propósito de la misma ya desde las constituciones de los propios estados, siendo copiosa la información también por lo que respecta al proceso constituyente federal.

En efecto, entre las cuestiones más importantes que se suscitaron se destaca el hecho de que la responsabilidad política se pudiera extender más allá del titular del ejecutivo sobre toda actuación de los oficiales de la administración que pudieran redundar en socavar el orden constitucional, así como la división de competencias y poderes entre las distintas ramas del gobierno, incluidos los jueces. La naturaleza del juicio político, en primer término, no es del orden criminal, ${ }^{12}$ en el sentido de que las conductas bajo su escrutinio no tienen por qué ser estrictamente procesables desde aquella rama jurídica. Su procedibilidad también estuvo sujeta a disputa: la frase "highcrimes and misdemeanors» de su precedente inglés resultó controvertible en sí misma y sigue siendo difícil de acotar. ${ }^{13}$. Así, algunos hablaban de que el juicio es idóneo en tanto el Presidente derive su administración en «un esquema de peculado u opresión»; cuando «abuse de su poder» o «corrompa a sus electores».

Francisco Berlín Valenzuela indica que la función de control parlamentario suele producir numerosos efectos de carácter político que pueden ir, en regímenes parlamentarios, desde un voto de censura o un voto de confianza, hasta la caída de un gobierno. Añade que en regímenes presidenciales, dado que la permanencia del Ejecutivo no depende del parlamento, los mecanismos de control son distintos. El control parlamentario - dice- puede producir el efecto de exhibir ante la opinión pública irregularidades de los funcionarios que no cumplen con las normas jurídicas, y puede dar lugar a la corrección de conductas de los servidores públicos y, en casos extremos, cuando proceda, iniciar el juicio político. ${ }^{14}$

Manuel González Oropeza, al analizar el papel del Senado de la República y de la Corte cómo órganos de jurisdicción política, señaló:

«...el Senado es un verdadero juez penal, aunque la sanción que puede aplicar es de carácter estrictamente político, o como lo diría Benito Juárez en la sesión del $1^{\circ}$ de abril de 1872 del Congreso de la Unión "el gran tribunal para los delitos oficiales de los altos funcionarios"». ${ }^{15}$

Por otra parte, al analizar los antecedentes del juicio político en los Estados Unidos de América, destacó:

${ }^{11}$ NEWMAN Jr., RICHARD K., «The Revival of Impeachment as a Partisan Political Weapon», Hastings Constitutional Law Quarterly, núm.34, 2006-2007, pp. 161-327, aquí p. 168.

${ }^{12}$ El juicio político es un procedimiento jurisdiccional constitucional per sé, reservado a la jurisdicción y competencia del órganos legislativos; se trata pues de un juicio constitucional cuya tramitación forma parte de los actos formalmente legislativos de naturaleza jurisdiccional del Congreso, de lo que se sigue que no forma parte de la justicia ordinaria.

${ }^{13}$ En el context americano, véase: Tribe, Lawrence, «Defining High Crimes and Misdemeanors: Basic Principles» George Washington Law Review, num. 67, 1999, pp. 712 y ss.

14 Vid., BERLÍN VALENZUELA, Francisco, Derecho Parlamentario. Fondo de Cultura Económica. Primera edición. Quinta reimpresión. México, 2003,141.

${ }^{15}$ GONZÁlEZ OROPEZA, Manuel, El Senado Mexicano. Por la razón de las leyes. Edición del Senado de la República, LIII Legislatura. Tomo III, Primera edición, México, 1987, p. 97. 
«Posteriormente, El Federalista número 65, escrito por Alexander Hamilton confirmaría esta crítica. El tribunal que juzgue a las causas políticas, necesita estar integrado por un cuerpo número de jueces, el procedimiento no debe ser tan rígido como el normal ante los tribunales comunes y no requiere de la existencia de jurados. Además, en caso de que hubiera delitos comunes qué perseguir, si la Suprema Corte decidiera sobre la responsabilidad política, estaría de hecho condenando al inculpado de la responsabilidad penal, pues los juzgados competentes inferiores se verían altamente influenciados por la decisión de la Corte.

Confirmando los anteriores argumentos, Joseph Story, uno de los defensores de esta función senatorial, explica que la función jurisdiccional del Senado en relación con los juicios políticos responde a la naturaleza de las acusaciones en contra de personales de la vida política de un país, así como a la flexibilidad de los procedimientos que el Senado debe observar, para Story, el Senado tiene la ventaja de estar integrado por funcionarios de elección popular que no dependen del Presidente para ser designados, desventaja que se observa con los ministros de la Suprema Corte y por la cual estarían imposibilitados para juzgar al presidente, vicepresidente o cualquier otro funcionario de la Administración Pública.

Story señala otra desventaja del Poder Judicial: consiste en que los ministros de la Corte pueden ser, ellos mismos, sujetos de un juicio político, tal como pasó en 1805 con el ministro de la Corte, Samuel Chase.» ${ }^{16}$

Por lo que hace al caso mexicano, y derivado de la desaparición del Senado, en el siglo XIX, consignó:

«2. Con la desaparición del Senado, México experimentó el sistema de la Suprema Corte como tribunal político, pero tan pronto como fue restablecido, el Senado comenzó con estas funciones.» ${ }^{17}$

El caso norteamericano también destaca por intentar hacer patente de forma más explícita la naturaleza «política» del procedimiento, en el sentido de que las acciones sancionables por el mismo son faltas contra el Estado, sus leyes o instituciones. Es decir, que su propósito está destinado a preservar el cumplimiento de la ley más que a la sanción o al castigo del funcionario en sentido técnico-penal. A este respecto es muy citada una definición de James Madison en El Federalista núm. 65, donde sostiene que la materia propia sujeta a juicio político bajo el escrutinio del Senado son: «aquellos delitos (o faltas) que proceden de la conducta indebida de los hombres públicos o, en otras palabras, el abuso o violación de un cargo público. Poseen una naturaleza que correctamente puede denominarse POLÍTICA (sic), ya que se relacionan sobre todo con daños causados de manera inmediata a la sociedad». ${ }^{18}$

De la misma forma, otra cuestión fue determinar ante qué rama del gobierno debía sustanciarse el juicio político. Así, cuando se deslizó la posibilidad de que el mismo fuese tra-

\footnotetext{
${ }^{16}$ GONZÁLEZ OROPEZA, Manuel, op. cit. pp. 97 y 98.

17 GONZÁLEZ OROPEZA, Manuel. op. cit p. 98.

${ }^{18}$ MADISON, James, The Federalist Papers, núm. 65, en: J. MADISON, J. JAY y A. HAMILTON, The Federalist [1778] ed. by G. W. CAREY and J. MCCLELLAN, Liberty Fund Inc. Indianapolis, 20o1, aquí p. 338.
} 
mitado ante el Senado y no ante un órgano jurisdiccional, salió a relucir la problemática de que - tramitado de esa manera - se haría demasiado dependiente o vulnerable al poder Ejecutivo del propio Legislativo. Sin embargo, que el Impeachment fuese competencia de un órgano jurisdiccional, sea la Suprema Corte o las Cortes Supremas de algún Estado, tenía también el inconveniente de que, al tratarse de cuerpos relativamente pequeños, los mismos podrían ser presas de cooptación política más fácilmente. Al final, como explicó el propio Madison, la convención constituyente se decantó por el Senado toda vez que: «¿Dónde sino en el Senado se hubiera podido encontrar un tribunal con bastante dignidad y la necesaria independencia?, ¿Qué otro cuerpo sería capaz de tener suficiente confianza en su propia situación para conservar libre de temores e influencias la imparcialidad requerida entre un individuo acusado y los representantes populares, que son sus acusadores». ${ }^{19}$

Así, podríamos señalar que la adaptación que los constituyentes norteamericanos hicieron del Impeachment de la tradición inglesa, en cuanto hace a sus aspectos más importantes, puede sintetizarse en los siguientes puntos. ${ }^{20}$

a)Limitación de los sujetos susceptibles de juicio político a «el Presidente, Vicepresidente y a todos los funcionarios civiles de los Estados Unidos».

b)Los constituyentes circunscribieron el abanico de conductas que podrían dar lugar al juicio político a «traición, cohecho u otros delitos y faltas graves»; ${ }^{21}$ mientras que, por el contrario, en la práctica inglesa el Parlamento siempre se mostró reticente a sujetar su jurisdicción a una lista «restringida» de causales.

c) Mientras la Cámara de los Lores puede condenar mediante mayoría simple, los delegados de la Convención Constituyente americana estipularon que en su desahogo ante el Senado «nadie puede ser condenada (y destituido de su encargo) sin la concurrencia de dos de las terceras partes de los miembros presentes».

d)Se limitan las sanciones aplicables a «la remoción del cargo y la inhabilitación para ocupar y ejercer cualquier empleo público sea honorífico, de confianza o remunerado en los Estados Unidos».

e) Mientras que el Rey podía otorgar en Inglaterra el perdón a cualquier persona que fuese condenado por juicio político; en los Estados Unidos se prohibió expresamente que el Presidente pueda ejercer una facultad de esas características.

f) Los constituyentes establecieron que el Presidente puede ser sujeto de juicio político; rompiendo con uno de los pilares del Impeachmentbritánico donde el Rey —la figura «próxima»- no lo era.

g)En el caso de los Estados Unidos se traza una línea divisoria más clara de la naturaleza política del juicio frente al eventual carácter penal que sí podía revestir en el caso inglés.

\footnotetext{
19 Ibid.

${ }^{20}$ Cf. GEHART, Michael J., "The Lessons of Impeachment History”, cit. pp. 605-606.

${ }^{21}$ De conformidad con el Artículo II de la Constitución Política de los Estados Unidos de Norteamérica. 
h) Por último, en Estados Unidos se estableció el juicio político como el único medio de esa naturaleza (política) para la remoción de jueces.

Por lo que respecta al procedimiento, la Constitución establece en su Artículo 1, Sección 2, que la Cámara de Representantes tendrá en exclusiva el poder de instaurar juicio político mientras que corresponde al Senado, también en términos de competencia exclusiva - dispuesto en la Sección 3 del mismo Artículo 1-, la facultad de tramitar todos los juicios políticos. Para sustanciar un juicio político, la Cámara de Representantes deberá aprobar, por mayoría de votos de sus miembros, la instauración de un procedimiento del que conocerá el Senado. Un Comité de la propia Cámara de Representantes actúa como fiscal acusador ante el Senado. La Cámara de Senadores sirve en el procedimiento como Tribunal. A excepción de aquellos casos de juicio político al Presidente de los Estados Unidos, donde el Presidente de la Suprema Corte preside; normalmente es el Senado quien desahoga todo el procedimiento convirtiéndose en jurado y quien en última instancia juzga. Como ya se señaló, la Constitución requiere de dos terceras partes de los miembros del Senado para que se pueda condenar a alguien. Normalmente, la sanción consiste en la remoción del funcionario público de su despacho y, en algunas ocasiones, a la misma le acompaña la inhabilitación para desempeñar cargos públicos en el futuro. El trámite no admite apelación alguna.

Existen, pues, notables diferencias entre la procedimiento de juicio político en los Estados Unidos respecto a su antecedente británico. En primer lugar, debe destacarse el hecho de que en el caso estadounidense nos encontramos ante una organización cuya forma de gobierno es una República Presidencial, su forma de Estado federal y la institución del control judicial de la constitucionalidad de las leyes. Es por ello que el procedimiento del juicio político suele tenerse, ante todo, como una forma de control político mutuo entre las distintas ramas del gobierno. Sin embargo, a diferencia de los regímenes parlamentarios, en los sistemas presidenciales la instauración de un procedimiento de juicio político básicamente se convierte en la posibilidad de que uno de los distintos poderes pueda ejercer un «veto» $\mathrm{o}$ «bloqueo» sobre los demás. Ello es así, recuérdese, porque en los regímenes parlamentarios el gobierno se forma siempre con el apoyo de la mayoría, algo que no sucede siempre en los regímenes presidenciales donde el Presidente puede eventualmente tener minoría en las distintas cámaras que integran el Legislativo.

Ahora bien, la propia existencia del juicio no excluye la posibilidad de que el mismo sea utilizado como «arma político-partidista». Ya el propio James Madison destacó el hecho de que el mismo pueda ser utilizado de manera facciosa entre adversarios, quienes se encargarán de reclutar a sus detractores - políticos o no- quienes actuando por intereses mezquinos, se alejan de la imparcialidad y de la altura de miras que las cuestiones de Estado precisan. «Siempre se corre el peligro de que la decisión sea tomada por la fuerza relativa de las facciones más que hechos reales a propósito de la inocencia o culpabilidad». ${ }^{22}$ La literatura a este respecto parece corroborar la utilización del juicio político como una «arma político-partidista». En efecto, si bien puede decirse que el procedimiento de juicio político presenta un rostro instrumental y por lo tanto «dual» en cuanto sus objetivos, toda vez que, efectivamente, si bien ha sido utilizado con la finalidad de proteger el imperio de la ley, también es cierto que su utilización ha devenido "partidista», con los problemas que ello puede generar en un régimen presidencial $(v . g r$. la imposibilidad de trabajar una agenda o incluso

\footnotetext{
${ }^{22}$ Cf. MADISON, James, The Federalist Papers, núm. 65, cit., p. 338.
} 
caer en la ingobernabilidad). En el caso norteamericano ello ha sido así de manera patente; sobre todo, a partir del año 1968, fecha en que el Impeachment ha sido frecuentemente utilizado de esta forma. ${ }^{23}$

La experiencia latinoamericana ${ }^{24}$ ha resultado en este punto más ejemplificativa de ese peligro. De modo paradigmático, en el caso de Paraguay en donde, prácticamente, se produjo un "golpe de Estado» con el derrocamiento del Ejecutivo a manos del Legislativo. Una coalición entre liberales y el Partido Conservador en el Congreso paraguayo utilizó ese procedimiento de manera sumaria y sin respetar el derecho a la defensa adecuada al entonces Presidente Fernando Lugo. Ello supuso básicamente que la oposición utilizó una vía reconocida constitucionalmente para privar al gobernante de la legitimidad que el electorado, a través de su voto, le había otorgado en las elecciones. Otras experiencias, sin embargo, son ambivalentes en la inestable realidad Latinoamericana. ${ }^{25}$

Señala Pérez-Liñan: «En condiciones ideales, los miembros del Congreso sólo iniciarían juicio político al presidente si hubiera prueba suficiente de un delito grave y no lo harían si las acusaciones tuvieran motivos meramente partidarios o personales. En la realidad sin embargo, los legisladores, rara vez pueden desprenderse del contexto social y político en el cual se produce una crisis presidencial». ${ }^{26}$

\section{CRÍTICA DEL JUICIO POLÍTICO}

La crítica del juicio político, como se desprende del anterior análisis, puede formularse teniendo presente tanto la experiencia británica como la estadounidense $-\mathrm{y}$ sobre todo esta última que es de donde nuestro sistema jurídico la incorpora-; así, de forma sucinta se destaca:

a) El juicio político - a pesar de su venerable historia ligada al control del poder - se considera una institución anacrónica en el país donde tuvo su origen. Ello es así porque la forma de gobierno británica evolucionó hacia la supremacía parlamentaria y, con ello, articuló por otros causes institucionales el conflicto político.

b) Por lo que respecta a la experiencia norteamericana, encontramos también elementos para su crítica derivada, fundamentalmente, de su utilización como «arma político-partidista».

c) La incorporación de un procedimiento de esta naturaleza tal en un sistema presidencial va a generar la posibilidad latente de que distintos actores tengan poder de «bloqueo» o «veto» en el funcionamiento de las otras ramas de gobierno, lo que redunda - paradójicamente y contra lo que en su origen fue su finalidad- en obstaculizar la división de poderes o en generar ingobernabilidad.

\footnotetext{
${ }^{23}$ Es la conclusión más significativa y que documenta a lo largo de su extenso trabajo: NEWMAN Jr., RICHARD K., «The Revival of Impeachment as a PartisanPolitical Weapon», cit.

${ }^{24}$ Véase: PÉREZ-LIÑÁN, Aníbal. Juicio Político al presidente y nueva inestabilidad política en América Latina. Traducción de Villegas, Silvia. Fondo de Cultura Económica. Primera edición en español 2009.

${ }^{25}$ Op. cit. PÉREZ-LIÑÁN, Aníbal, p. 258

${ }^{26}$ Op. cit. PÉREZ-LIÑÁN, Aníbal, p. 215. 


\subsection{REFERENCIA AL JUICIO POLÍtico EN GUANAJUATO}

La figura del Juicio Político, a la fecha, sólo procede en los términos de los artículos 109, 110 y 114 de la Constitución Política de los Estados Unidos Mexicanos. ${ }^{27}$

Para reglamentar la aplicación de la figura del Juicio Político, el entonces Gobernador del Estado, Lic. Enrique Velasco Ibarra, presentó ante la Quincuagésima Segunda Legislatura del Congreso del Estado, la Iniciativa de Ley de Responsabilidades de los Servidores Públicos del Estado de Guanajuato, consignando la exposición de motivos:

«El capítulo primero del título segundo contiene las normas que el Congreso del Estado ha de observar en aquellos casos en que el Congreso de la Unión emita sentencias declarativas en los juicios políticos de su competencia y declaraciones de procedencia en materia penal federal.

Si bien es cierto que tanto las resoluciones del Senado como las de la Cámara Federal de Diputados, son intocables, correspondiendo al Congreso Local aplicar la sanción de destitución o inhabilitación, se le faculta para el análisis de cada caso, a fin de que con la mayor información posible decida sobre la naturaleza y gravedad de la sanción. Se ha considerado conveniente que la Comisión de Justicia conozca del expediente y oyendo en defensa del inculpado, dentro de un plazo prudente, produzca dictamen, mismo que será sometido al Congreso para que, por mayoría de las dos terceras partes, cuando menos, resuelva en definitiva sobre la sanción aplicable. Tratándose de la declaración de procedencia, el procedimiento es análogo, dejando en su caso al inculpado a disposición de las autoridades jurisdiccionales competentes y decretándose la suspensión de la función, en la inteligencia de que el inculpado podrá volver a su cargo cuando la acción penal no prospere, ya que la resolución del Congreso no prejuzga sobre los fundamentos de la acusación.» ${ }^{28}$

\footnotetext{
${ }^{27}$ El artículo 113 de la Constitución General de la República a partir de 1982 establece por primera vez a nivel constitucional, las bases para la responsabilidad administrativa de los servidores públicos. El texto original en 1917 del artículo 113 preveía (en forma idéntica al artículo 107 de la Constitución de 1857) que la responsabilidad por «delitos y faltas oficiales» sólo podía exigirse durante el periodo en que el «funcionario» ejercía su encargo y dentro del año siguiente, lo cual ahora se contempla en forma similar, para las responsabilidades de los servidores públicos derivadas del juicio político, en el primer párrafo del artículo 114 constitucional. El vigente artículo 113 prescribe que corresponderá a las leyes sobre responsabilidades administrativas de los servidores públicos (ya se trate de la Federal o de una Entidad Federativa, según su ámbito de competencia) determinar las obligaciones administrativas de los mismos, las sanciones por los actos u omisiones en que incurran, así como los procedimientos y las autoridades para aplicarlas. Igualmente, prevé ciertas características que deberán satisfacer las sanciones administrativas que se determinen legislativamente. De modo que el artículo 113, junto con la fracción III del 109 y el 114, contemplan la responsabilidad administrativa de los servidores públicos, «a fin de salvaguardar la legalidad, honradez, lealtad, imparcialidad y eficiencia en el desempeño de sus funciones, empleos, cargos y comisiones.» Además el artículo 113 guarda estrecha relación con los demás preceptos del Título Cuarto de la Constitución, particularmente con el 108, que define quienes deben ser considerados como servidores públicos para los efectos de las responsabilidades consiguientes; con el 109, que regula las diversas clases de los servidores públicos, incluyendo las de carácter administrativo, y con el 114, que establece los plazos en que prescriben las distintas responsabilidades, particularmente por lo que hace a las administrativas.

${ }^{28}$ Exposición de motivos de la Iniciativa del Ejecutivo que contiene la Ley de Responsabilidades de los Servidores Públicos del Estado de Guanajuato. Diario de los Debates de la Cámara de Diputados del Congreso del Estado de Guanajuato. Año II. Periodo extraordinario de sesiones. LII Legislatura. Tomo II. Número 6. Sesión del 2 de marzo de 1984, p. 3.
} 
El dictamen de las Comisiones Unidas de Gobernación, Puntos Constitucionales y de Justicia, consignó:

«2.- En cuanto al capítulo primero del título segundo que contiene las normas que el Congreso del Estado ha de observar en aquellos casos en que la Cámara de Senadores o de Diputados del Congreso de la Unión emitan, según su competencia, sentencias declarativas en juicios políticos y declaraciones de procedencia en materia penal federal en contra del Gobernador del Estado, diputados locales y magistrados del Supremo Tribunal de Justicia, se conservó casi íntegra la redacción de la iniciativa, modificándola en cuanto que dichas sentencias declarativas deberán estar justificadas para que se declaren procedentes.» ${ }^{29}$

Posterior a la ley de 1984, el entonces Gobernador del Estado del Estado, Vicente Fox Quezada, promovió una iniciativa de nueva ley de la materia ante la Quincuagésima Séptima Legislatura, y agotado el trámite del proceso legislativo en el Congreso, ejerció su facultad de veto sobre el Decreto 75, relativo a la Ley de Responsabilidades de los Servidores Públicos al Servicio del Estado y los Municipios de Guanajuato, conforme lo establecido por el artículo 58 de la Constitución Política para el Estado, ingresando el veto en la sesión de Pleno de 23 de junio de 1998, durante la Quincuagésima Séptima Legislatura, instruyendo la presidencia su turno a las Comisiones Unidas de Gobernación y Puntos Constitucionales, y de Justicia, en su carácter de Comisiones Dictaminadoras, conforme lo dispuesto por el artículo 82 de la entonces vigente Ley Orgánica del Poder Legislativo, para su estudio y dictamen.

El veto fue heredado a la Quincuagésima Novena Legislatura del Congreso del Estado, dentro del proceso de entrega-recepción, y posteriormente, en la sesión de Pleno de 10 de junio de 2004, ingresó la iniciativa suscrita por el Gobernador del Estado de Ley de Responsabilidades de los Servidores Públicos del Estado y los Municipios de Guanajuato, entrando a su análisis y dado que la iniciativa propuesta por el Titular del Poder Ejecutivo, superaba en contenido normativo al Decreto 75 emitido por la LVII Legislatura, además de que actualizaba varias instituciones que se han modificado de 1998 - fecha del veto-, pues habían transcurrido siete años desde la aprobación de la Ley de Responsabilidades de los Servidores Públicos al Servicio del Estado y los Municipios vetada es que al dictaminar de la iniciativa remitida por el Gobernador, y aprobarse esta por el Congreso del Estado el proyecto de decreto que se plantea, se decretó igualmente el archivo del Decreto 75 relativo a la Ley de Responsabilidades de los Servidores Públicos al Servicio del Estado y los Municipios de Guanajuato, así como del veto del Gobernador del Estado, por quedar ambos sin materiazo.

La Iniciativa de la vigente Ley de Responsabilidades Administrativas de los Servidores Públicos del Estado de Guanajuato consignó en la exposición de motivos, respecto de la figura de Juicio Político, la conveniencia de que se regule en la Ley Orgánica del Poder Legislativo:

\footnotetext{
${ }^{29}$ Dictamen de las Comisiones Unidas de Gobernación, Puntos Constitucionales y de Justicia. Diario de los Debates de la Cámara de Diputados del Congreso del Estado de Guanajuato. Año II. Periodo extraordinario de sesiones. LII Legislatura. Tomo II. Número 7. Sesión del 27 de marzo de 1984, p. 8.

${ }^{30}$ El presente trámite legislativo, encentró sustento en el precedente que se tuvo con la aprobación de la Minuta de Reforma Constitucional, durante la Quincuagésima Sexta Legislatura, a través del Decreto 19, publicada en el Periódico Oficial del Gobierno del Estado número 91 segunda parte, de 15 de noviembre de 1994, en la que a través del artículo sexto transitorio, se dejó sin efecto la Minuta Proyecto de Decreto no promulgada ni publicada, cuya declaratoria fue emitida por la Quincuagésima Quinta Legislatura; considerándose pues, 
«Por otra parte, en la iniciativa se propone que el contenido del Título Segundo de la vigente Ley de Responsabilidades, en su caso, sea regulado por la Ley Orgánica del Poder Legislativo del Estado de Guanajuato, ya que las cuestiones relativas al juicio político y a la declaración de procedencia por delitos del orden común, son procedimientos esencialmente parlamentarios que deben comprenderse, naturalmente, en la Ley Orgánica del referido Poder Legislativo; toda vez que desde su origen en el sistema inglés y en el sistema americano, las responsabilidades políticas y jurídico-penales de funcionarios amparados por la garantía de inmunidad, han sido una materia propia del Parlamento o Poder Legislativo, por la naturaleza de la garantía y por la intervención decisoria de este Poder, bien para la sanción de carácter político y para la declaración de procedencia, que permite la sujeción al orden jurisdiccional por la presunta responsabilidad en la comisión de delitos." ${ }^{31}$

El dictamen de las Comisiones Unidas de Gobernación y Puntos Constitucionales, y de Justicia, consignó al respecto — de la abrogación-:

«V. Modificaciones a la Iniciativa.

Después del análisis y valoración de las observaciones de los Grupos Parlamentarios y ayuntamientos, se realizaron los siguientes cambios:

1. Se modificó la denominación del cuerpo normativo, para quedar como: "LEY DE RESPONSABILIDADES ADMINISTRATIVAS DE LOS SERVIDORES PÚBLICOS DEL ESTADO DE GUANAJUATO Y SUS MUNICIPIOS”, ello en razón de que la única responsabilidad que regulará es la administrativa, atentos a que se omiten las disposiciones que se contemplan en la vigente Ley de Responsabilidades de los Servidores Públicos del Estado de Guanajuato, en el Título Segundo, capítulos primero y segundo, relativas al juicio político y declaración de procedencia en materia penal federal, y declaración de procedencia por delitos comunes.

De hecho, el artículo 113 de la Constitución Política de los Estados Unidos Mexicanos, sustento de las leyes de responsabilidades, las refiere como "Las leyes sobre responsabilidades administrativas de los servidores públicos..., por lo que con la nueva denominación, nos ajustamos al texto constitucional federal.» ${ }^{32}$

De 2005 a la fecha, no se ha legislado para incorporar la regulación del juicio político en la Ley Orgánica del Poder Legislativo.

En este sentido, se destaca: 1. El antecedente que consta en el Diario de los Debates, consideró que el espacio idóneo para la regulación del Juicio Político es la Ley Orgánica del Poder

innecesario emitir un dictamen diverso para archivar el Decreto $75 \mathrm{y}$ el veto del Gobernador del Estado, por haber quedado ambos sin materia.

${ }^{31}$ Diario de los Debates de la Cámara de Diputados del Congreso del Estado de Guanajuato. Segunda Época. Año II. LIX Congreso Constitucional del Estado. Tomo I. Número 87. Sesión del 28 de abril de 2005, p. 45.

32 Dictamen emitido por las Comisiones Unidas de Gobernación y Puntos Constitucionales, y de Justicia, relativo a la Iniciativa de Ley de Responsabilidades de los Servidores Públicos del Estado y los Municipios de 
Legislativo, porque es un procedimiento esencialmente parlamentario; 2. La naturaleza del Juicio Político, es de carácter jurídico-político, sin embargo dicha figura ha resultado totalmente ineficaz en el orden jurídico mexicano, donde se ha probado su nula aplicabilidad, dado que mediante dicha figura, no se ha revocado el mandato y ni se ha suspendido a funcionario alguno, ni el orden local, ni el orden federal; 3. A la fecha -tanto por la incorporación del Sistema Nacional Anticorrupción, como por otras modificaciones legislativas-, debe tenerse presente que la tendencia parece dirigirse en el establecimiento otras formas de rendición de cuentas más técnico-jurídicas - o imparciales, si se quiere ${ }^{33}-\mathrm{y}$, en esa medida; pero que debe tenerse todo el cuidado para no confundirse con estos, sobreponiéndolas o diezmándolas, no sujeta a los vaivenes políticos de un momento determinado.

Es de considerar que en el estado de Guanajuato recientemente se han presentado dos iniciativas - ambas por el Grupo Parlamentario del Partido Revolucionario Institucional_, las cuales han buscado impulsar tanto una reforma constitucional con la finalidad de ampliar los sujetos susceptibles a la aplicación de dicho mecanismo y el procedimiento a seguir, lo que se complementaría con la iniciativa de Ley de Juicio Político del Estado; la primera de las iniciativas fue ya dictaminada en sentido negativo, consignado el dictamen:

\section{De archivo argumenta:}

«Quienes dictaminamos estimamos que los poderes legislativos no se han caracterizado por ser buenos órganos jurisdiccionales en la impartición de justicia, en virtud de que su función por excelencia es netamente legislativa, de igual forma creemos que el Juicio Político está regulado por nuestra normatividad actual, en el artículo 124 de la Constitución Local donde nos señala que el Gobernador del Estado, los Diputados Locales y los Magistrados del Supremo Tribunal de Justicia, podrán ser sujetos a juicio político, para ello se aplicarán las normas referidas en los artículos 109, 110 y 114 de la Constitución Política de los Estados Unidos Mexicanos.

Esto es, se colige que para la instauración de un Juicio Político, cualquier ciudadano, bajo su más estricta responsabilidad y mediante la presentación de elementos de prueba, podrá formular denuncia ante la Cámara de Diputados. En caso de ser procedente la declaración y resolución del Congreso de la Unión será inatacable, y comunicada a la Legislatura Local señalando que para el caso del Gobernador del Estado, Diputados Locales, Magistrados del Supremo Tribunal de Justicia y, en su caso, los miembros del Consejo del Poder Judicial la resolución será únicamente para efectos declarativos y se comunicará a la Legislatura Local para que, en ejercicio de sus atribuciones, proceda como corresponda, de acuerdo con la normatividad vigente aplicable.

Como puede advertirse, en el Estado está regulado el Juicio Político, por lo tanto, no se considera pertinente legislar en esta materia, resultando viable, en todo caso, entrar al

Guanajuato, formulada por el Gobernador del Estado.

${ }^{33}$ Que sea así, puede desprenderse de la procedibilidad de mecanismos de tutela constitucional como la acción de constitucionalidad sobre el otrora irrecusable juicio político. Ello se explica fundamentalmente a que con el mismo se trastoca la división de poderes. Véase: Tesis aislada LVII/2005, del Pleno de la Suprema Corte de Justicia de la Nación, derivada de la Controversia Constitucional 106/2004, Novena Época, Semanario Judicial de la Federación y su Gaceta, Tomo XXIII, de enero de 2006, p. 2066. 
estudio de la Ley de Responsabilidades Administrativas de los Servidores Públicos del Estado de Guanajuato y sus Municipios, por ser esta el espacio idóneo y no una ley especial.

Es indudable que la responsabilidad política recae en aquellos servidores públicos que en el ejercicio de sus facultades ejercen actos de gobierno y en su caso actos de administración, por lo que todos aquellos actos u omisiones en que incurran tales servidores públicos, serán sujetos de responsabilidad política, cuya sanción en caso de comprobar dicha responsabilidad podrá ser la destitución del cargo, así como su inhabilitación. Luego entonces, por la naturaleza del juicio político, de los órganos que intervienen en el desahogo del procedimiento así como su ubicación o adscripción formal, se propone que siga conociendo el Congreso del Estado como órgano político, sin que intervenga el Poder Judicial. Por ello, con base a tales consideraciones los integrantes de esta comisión no llegaron a un consenso sobre la iniciativa que hoy se dictamina, proponiéndose continuar con el estudio y análisis de este tema, a fin de que esta legislatura adecue y perfeccione el sistema de responsabilidades de los servidores públicos adscritos a los poderes del Estado.

Así mismo, por la naturaleza del Juicio Político, la iniciativa de reforma al considerar en su segundo párrafo que se hará la acusación respectiva ante el pleno del Supremo Tribunal de Justicia del Estado, se está incluyendo a un órgano jurisdiccional, que no tiene competencia constitucional para conocer de un procedimiento de esta naturaleza.

Desvirtuándose con ello la instauración y desahogo del juicio político, cuyos órganos competentes para su conocimiento son el Congreso de la Unión y la Legislatura del Estado [sobre el particular, la Coordinación General Jurídica, a través del Oficio D.A.L.R. 200/2013, argumentó: «En este sentido, en atención a que el proyecto busca generar la participación de dos poderes, el Legislativo y el Judicial, en el proceso de Juicio Político, se considera que no es lo favorable, ello en atención a: 1. el antecedente que consta en el Diario de los Debates, donde se consideró que el espacio idóneo para la regulación del Juicio Político es la Ley Orgánica del Poder Legislativo, porque es un procedimiento esencialmente parlamentario; 2. La naturaleza del Juicio Político, es de carácter jurídico político, por lo que involucrar al Poder Judicial, que es un órgano de aplicación de la justicia de estricto derecho, en un proceso en parte de naturaleza política, se estima no conveniente; además, que rompe con el modelo que se ha seguido en México (no obstante que algunas entidades, como Morelos, lo incorporen), pues implica dilatar la eficacia de éste, al constar de dos etapas, una que se desahogaría en el Congreso del Estado y la segunda ante el Pleno del Supremo Tribunal de Justicia]».

Como corolario a las anteriores consideraciones, nos permitimos citar a José Elías Romero Apis quien señala que son cuatro las grandes y graves deficiencias que padece la institución del juicio político, no sólo en México sino en el mundo, mezcla de proceso y partidismo: su frágil madurez, su precario profesionalismo, su débil imparcialidad y su tenue credibilidad. Por ello, dice, sus escenarios pasados, presentes y futuros han sido de triste memoria, de escasa expectativa y de pobre perspectiva. Esta Comisión considera bastante ilustrativas las siguientes palabras de José Elías Romero Apis: 
«El reto de las sociedades modernas... estriba en el uso que deberá darse a un instrumento de justicia que no es el mejor brazo de la política y a un instrumento de la política que no es el mejor brazo de la justicia.

«...En buena hora la exigencia de responsabilidad en el ejercicio del servicio público. En hora buena que, también, se castigue al trasgresor de la ley (gobernante o no). Mal uso de poder el que rechaza todo proceso político. Mal uso de poder el que, por el contrario, acepta todo proceso político.

«Confiemos en que no habremos de caer en el grave error de hacer de la justicia la solución de la política, ni en el grave pecado de hacer de la política la solución de la justicia.

Por las consideraciones y argumentos expuestos, consideramos no atendible la propuesta formulada por los y las iniciantes, al no generarse el consenso unánime de esta Comisión Dictaminadora, de acuerdo a lo anterior, estimamos pertinente proponer el archivo de la iniciativa descrita en el presente dictamen.» ${ }^{34}$

La segunda Iniciativa, aún pendiente de dictaminar al momento, propone igualmente la reforma el artículo 124 de la Constitución Política del Estado de Guanajuato y la expedición de la Ley de Juicio Político para el Estado de Guanajuato, se presentó el 12 de marzo de 2015.

\section{CONCLUSIONES}

1. El espacio idóneo para regular la figura del Juicio Político es la Ley Orgánica del Poder Legislativo, sin que se amplié el catálogo previsto en la Constitución Federal, el cual además deberá ser respetuoso de la garantía de audiencia; con la intención de colmar el vacío legal que hasta ahora existe en el ordenamiento jurídico local en la materia.

2. El procedimiento a regular deberá ser breve, efectivo y transparente con la finalidad de no limitar el ejercicio de las funciones de los servidores públicos sin causa probada, impactando así de manera negativa al cumplimiento de los fines del Estado.

3. El avance que se ha tenido con la reforma constitucional en materia del Sistema Nacional Anticorrupción dejó intocada la figura del Juicio Político, la que nada su naturaleza de proceso jurídico-político deviene de origen en su no eficacia, como se ha comprobado en el orden federal y estatal, de ahí que sería recomendable que en los ejercicios y reflexiones que seguramente habrán de darse con motivo del centenario de la promulgación de la Constitución de $1917,{ }^{35}$ se valore la eficacia de dicha institución.

\footnotetext{
${ }^{34}$ Dictamen de la Comisión de Gobernación y Puntos Constitucionales de la Iniciativa de reforma al artículo 124 de la Constitución Política del Estado de Guanajuato y de la Ley de Juicio Político para el Estado de Guanajuato. Diario de los Debates de la Cámara de Diputados del Congreso del Estado de Guanajuato. Año II. LXII Legislatura. Número 59. Sesión del 21 de noviembre de 2013, pp. 90 y 91.

${ }^{35}$ A modo de ejemplo, el Instituto de Investigaciones Jurídicas de la UNAM en coordinación con el Instituto Iberoamericano de Derecho Constitucional, han realizado una revisión técnica del texto constitucional, denominado: «Constitución Política de los Estados Unidos Mexicanos. Texto reordenado y consolidado. Estudio académico». Consultable en: http://www2.juridicas.unam.mx/constitucion-reordenada-consolidada// 
4. FUENTES

BIBLIOGRÁFICAS

BERLÍN VALENZUELA, Francisco, Derecho Parlamentario, Fondo de Cultura Económica. Primera edición. Quinta reimpresión. México, 2003.

BROWN FIRMAGE, Edwin, «The Law of Presidential Impeachment», Utah Law Review.

GAY, Oonagh y DAVIES,Neris, «Impeachment», House of Commons Library Standard Note, SN/PC/o2666, 2011, p. 3. Consultable en: http://www.parliament.uk/briefingpapers/SNo2666/impeachment

GEHART, Michael J., «The Lessons of Impeachment History», George Washington Law Review, num. 67, 1999.

GONZÁLEZ OROPEZA, Manuel. El Senado Mexicano. Por la razón de las leyes. Edición del Senado de la República, LIII Legislatura. Tomo III, Primera edición, México, 1987.

MADISON, James, The Federalist Papers, núm. 65, en: J. MADISON, J. JAY y A. HAMILTON, The Federalist [1778] ed. by G. W. Carey and J. MCCLELLAN, Liberty Fund Inc. Indianapolis, 2001.

NEWMAN JR., Richard K., «The Revival of Impeachment as a Partisan Political Weapon», Hastings Constitutional Law Quarterly, núm. 34, 2006-2007.

PÉREZ-LIÑÁN, Aníbal, Juicio Político al presidente y nueva inestabilidad política en América Latina. Traducción de Villegas, Silvia. Fondo de Cultura Económica. Primera edición en español 2009.

TRIBE, LAWRENCE, «Defining High Crimes and Misdemeanors: Basic Principles» George Washington Law Review, num. 67, 1999.

\section{DOCUMENTALES}

Diario de los Debates de la Cámara de Diputados del Congreso del Estado de Guanajuato. Año II. Periodo extraordinario de sesiones. LII Legislatura. Tomo II. Número 6. Sesión del 2 de marzo de 1984.

Diario de los Debates de la Cámara de Diputados del Congreso del Estado de Guanajuato. Año II. Periodo extraordinario de sesiones. LII Legislatura. Tomo II. Número 7. Sesión del 27 de marzo de 1984.

Diario de los Debates de la Cámara de Diputados del Congreso del Estado de Guanajuato. Segunda Época. Año II. LIX Congreso Constitucional del Estado. Tomo I. Número 87. Sesión del 28 de abril de 2005. 